\title{
Biodiversity of anaerobic fungi from ruminants in republic of Macedonia
}

\begin{abstract}
Anaerobic chytridiomycete fungi are found in the gastrointestinal tracts of sheep, cattle and goats, as well as in many other domesticated ruminant and nonruminant herbivores and a wide variety of wild herbivorous mammals. They are principally found associated with the fibrous plant particles of digesta and as free swimming zoospores in the fluid phase. The presence of large fungal populations in animals consuming mature pasture or diets largely composed of hay or straw together with the production of highly active fibre degrading enzymes lead to the belief that anaerobic fungi may have a significant role to play in the assimilation of fibrous feeds by ruminants. This paper is focused on anaerobic fungi because of their unusual biology and metabolism, and the biotechnological potential of their cellulases.
\end{abstract}

Keywords: anaerobic fungi, chytridiomycete, ruminant, herbivores, zoospores, cellulases
Volume I Issue 3 - 2017

\author{
Atanasova-Pancevska N, Kungulovski D \\ Department of Microbiology and Microbial Biotechnology, \\ Saints Cyril and Methodius University of Skopje, Macedonia \\ Correspondence: Natalija Atanasova-Pancevska, Department \\ of Microbiology and Microbial Biotechnology, Institute of \\ Biology, Faculty of Natural Sciences and Mathematics, Saints \\ Cyril and Methodius University of Skopje,Arhimedova 3, Skopje, \\ Macedonia, Email natalijaap@gmail.com
}

Received: August 18,2017| Published: October 20, 2017

\section{Introduction}

Herbivores as well as other vertebrates are not capable of producing cellulases and/or hemicelullases. Instead, a lot of herbivores form symbiotic associations with bacteria, protozoa and fungi which produce these enszymes and therefore are capable of degrading the plant polymers. In return for the relatively constant environment and continuous flow of plant material, the microorganisms of the herbivores' digestive system provide the animal with easily usable form of carbon and energy, and ruminants with microbial proteins. Microbial eco-system of rumen is stable and at the same time dynamic. ${ }^{1}$ Stability is seen in the fact that the system itself is set well, in function and bioconversion of food in volatile fatty acids. In healthy ruminants, there is no contamination of eco-system although millions of microorganisms attack the rumen every day via food, water and air. Namely, this happens because rumen-microorganisms are adapted to survive the conditions in the rumen, whereas contaminants do not survive. They are anaerobyosis, high buffer capacity and osmotic pressure. On the other hand, the eco-system is dynamic due to the change of microbial population by changing food and frequency of feeding.

The only ultra structure of anaerobic fungi, their adaptation of gastrointestinal tract of herbivores and their habitation among phylogenetically different animals teaches us that they could exist as a separate group until the time when these mammals had started diverging, at least 120 million years ago. ${ }^{2}$ Although comparatively a little is known for the taxonomy of anaerobic fungi, generally it is known that they are zoospore-producing fungi and should belong to the classis of Chytridiomycetes. The order Spizellomycetales in Chytridiomycetes was established by Barr ${ }^{3}$ with the division of Chytridiales in order to explain the differences in the ultra structure of zoospores. Anyway, there are a lot of similarities between the families and genera from both or dines (Spizellomycetales and Chytridiales). Six ordines are known: Neocallimastix, Piromyces, Orpinomyces, Anaeromyces, Caecomyces, and since recently Cyllamyces. ${ }^{4}$ In Republic of Macedonia this is the first study to process anaerobic fungi in domestic and wild rumen animals.

\section{Materials and methods}

\section{Source of organisms}

Anaerobic fungi were isolated from rumen content and feces from more domestic and wild herbivorous mammals. Animals which took participation in this paper are given in Table 1. Feces was taken in several occasions around 10.00-10.30am and was picked up fresh from the ground and was taken immediately to the laboratory. Also, feces which has been old only several days was used. Only in one case was feces used, directly taken from the moufflon's large intestine. Rumen content was taken during slaughtering, direclty from rumen, after which was taken to laboratory immediately.

\section{Medium for isolation and cultivation}

Many of the cultivation techniques and media which are used in rumen-microbiology originate from Hungate ${ }^{5,6}$ who studied anaerobic rumen bacteria. These techniques were modified and upgraded in order to provide media and procedures which are nowadays used constantly in the anaerobic microbiology. ${ }^{7}$ With relatively few exceptions, these media and techniques are used today, together with anaerobic bags and procedures with Petri dish ${ }^{8,9}$ for isolation and studying of anaerobic fungi. The basic medium which was used to isolate anaerobic fungi, was the medium 10 (M10) of. ${ }^{10}$ Medium M10 is one of the numerous media used in anaerobic rumen-microbiology and for our region and climate, ideal. It contains rumen fluid and that is why it is described as complex or habitat-simulating; it is well buffered at $\mathrm{pH}$ from 6.5 to 6.8 with bicarbonate and/or phosphate buffers and might be solidified with $0.8-1.5 \%$ agar. The medium contains resazurin as redox indcator, micro and macrominerals, organic and/or inorganic nitrogen sources and chemically reducing agentives, sodium sulfate and/or L-cystin hydrochloride. ${ }^{11}$ Reducing agets and anaerobic techniques are essential during medium preparation. One or more antibacterial antibiotics, penicillin, streptomycin and chloramphenicol incorporate in the medium; this is essential during isolation of anaerobic fungi from rumen content and faecal samples. ${ }^{12}$ In fact, antibiotics are necessary because of the anaerobic fungi growth which is completely inhibited in co-culture in anaerobic rumen bacteria. 
In order to isolate axenic cultures from anaerobic fungi from their natural environment, free from contaminated bacteria, it is essential that repetitive subcultures are used, antibacterial antibiotics and some form of physical separation, such as cultivation of isolated colonies of agar medium.

Table I Animals used in this paper

\begin{tabular}{ll}
\hline Animal & $\begin{array}{l}\text { Origin of the animal (Type of } \\
\text { animal- phylum) }\end{array}$ \\
\hline Cattle(Bos indicus) & Z (R) \\
Domestic yak (Bos gruniens) & Z (R) \\
Ankole-watusi (Bos vatusi) & Z (R) \\
Red deer (Cervus elaphus) & Z, J (R) \\
Fallow deer (Cervus dama) & Z,J (R) \\
Barbary sheep (Ammotragus & Z (R) \\
lervia) & Z (R) \\
Pygmy goat (Capra nigra spp.) & Z, J (R) \\
Roe deer (Capreolus capreolus) & J (R) \\
Mouflon (Ovis musimon) & D (R) \\
Wild water buffalo (Bos bubalus) & D (R) \\
Sheep (Ovis aries) & D (R) \\
Goat (Capra hircus) & J (R) \\
Chamois(Rupucapra rupicapra) & \\
\hline
\end{tabular}

Z, ZOO; J, Protected Nature Reserve Jasen; D, Domestic Animal; R, Ruminant Animal.

\section{Determination of morphological features of obtainedisolates}

In order to study the morphology and anatomy of the obtained pure isolates, cultivated in liquid medium M10, they have been additionally observed by applying the lighting and fluorescent microscopy, in different stages of their development. For that puprose, there had been a native preparation which was coloured with safranin and was directly observed. To observe some of the isolates, for which the lighting microscopy did not give enough data, fluorescent microscopy was also used where a drop of suspension was mixed with fluorochrome colour and bisbenzimide (5mg/l PBS) to color the nuclei. The Nicleiturn fluorescent when lightened by UV light. They were determined accordingly the morphology of colonies, volume of fungal rhizoids and appearance of zoospores, with regards to. ${ }^{13}$

\section{Result and discussion}

There are two morphological forms, monocentric (one reproductive body) and polycentric (more centres of reproduction). These forms are determined in the earliest stages of development and are invariable. In both forms, after zoospore encystation, the cyst germinates with producing germinative tube. In monocentric types, the nucleus does not enter the germinative tube. The germinative tube develops in rhizodal system with determined length. Anuclear rhizoids have double usage, grounding and absorption of nutrients. Rhizoids are of two types: typical filamentous form in Neocallimastix and Piromyces, and bulbous form in Caecomyces.

In polycentric types (Orpinomyces and Anaeromyces) the nucleus migrates outside the zoospore cyst in the germinative tube. The zoospore cyst does not have a further function in the development, but the cyst wall might remain. The germinative tube elongates and ramifies in mycelium (rhizomycelium) similar to other filamentous fungi. The nucleus ramifies constantly and migrates along the individual hyphae. This form of development results in mycelium thallus with unpredictable volume with many sporangia. Unfortunately, after the continuous culture, many of the mycelium polycentric types either produce sporangia which do not differentiate in zoospores, or they do not produce sporangia anymore, and their identification becomes problematic.

In identifying chytrids, it is essential not to forget their natural morphological variation. This variation complicates the identification and classification of these organisms. Because of the temperature needs and anaerobic status of anaerobic fungi, the problem is amplified and compared to the other chytrids, growth and development of one thallus cannot be studied microscopically under normal circumstances. The differences in the medium probably contribute to more variations rather than any other factor. When the medium is too rich, as in the glucose or in filter paper, the sporangia often become abnormally big and abort. Small but mature thalli of monocentric types, except C.communis, are similar and only by observing of the type of discharge of zoospores and zoospores flagellation, they might differ. When anaerobic fungi are identified and classified, it is essential to make sure the sporangia are healthy and viable, and conclusions should be reached only after enough material had been observed.

In addition, there is a description of obligatory anaerobic fungi, which have been isolated during the preparation of this study. The description is based completely on the thallus morphology, as seen through the light microscope, in order to enable functional identification of genera and phyla.

\section{Isolate EZ}

Endogenously developed zoosporangia, spheric with diameter of $65.71 \mu \mathrm{m}$; rhizoids mainly come over from one axis, occasionally two or three at the same side of the sporangium, the neck is wide; the main axis close to the sporangium, up to $20 \mu \mathrm{m}$ in diameter; main rhizoid is often coiled; rhizoids might have strongly narrowed places, rhizoid system is spread up to $1 \mathrm{~mm}$ in diameter, zoospores are liberated through apical pore.

The isolate is taken from feces of a fallow deer (Cervus dama), kept in the ZOO, Skopje. Accordingly the key to determine the anaerobic fungi of, ${ }^{13}$ the description of the isolate corresponds completely to the description of Neocallimastix frontalis.

In Malaysia, $N$. frontalis has been isolated from rumen material and droppings from a buffalo, ox, sheep, goat and deer. ${ }^{14}$ Also, rumen material has been isolated from oxen in New Zealand, ${ }^{15}$ Canada, ${ }^{16}$ Australia ${ }^{17}$ and $\mathrm{USA}^{18}$ and from the rumen, the saliva and droppings from sheep in Great Britain ${ }^{19,20}$ (Figure 1) (Figure 2).

\section{Isolate EZ2}

Endogenously developed zoosporangia, spherically elongated (egg-like); $157.14 \mu \mathrm{m}$ in diameter; rhizoids mainly come over from one axis, occasionally two or three at the same side of the sporangium, the neck is wide; the main axis close to the sporangium, up to $17.14 \mu \mathrm{m}$ in diameter, coiled; main rhizoid is often coiled; rhizoid might have strongly narrowed places; rhizoid system is spread up to $1 \mathrm{~mm}$ in diameter, zoospores are liberation through apical pore, accompanied by fast decomposition and cracking of the sporangium wall; zoospores 
are variable in length and shape, globular zoospores with $10-25 \mu \mathrm{m}$ in diameter, with 10 to 30 flagella, $35-50 \mu \mathrm{m}$ long.

The isolate is taken from feces of a fallow deer (Cervus dama), kept in the ZOO, Skopje. Accordingly the key to determine the anaerobic fungi of ${ }^{13}$ the description of the isolate corresponds completely to the description of Neocallimastix frontalis (Figure 3).
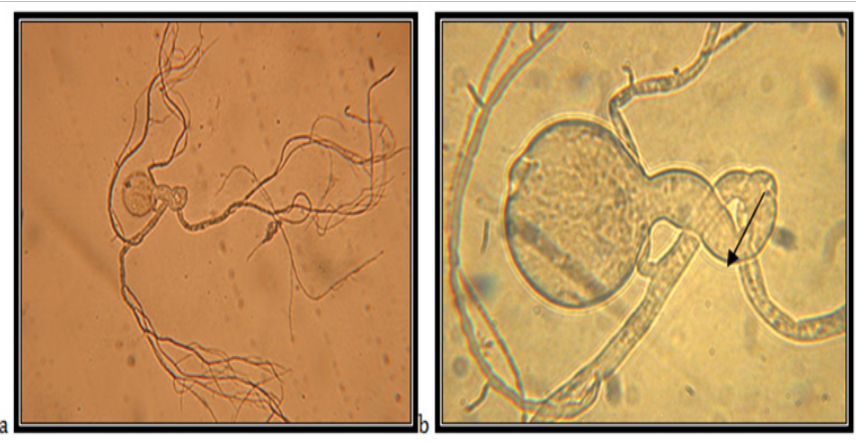

Figure I Strain EZI - N. frontalis. Monocentric thallus with one sporangium, wide neck, main rhizoid coiled (narrow).a, Magnification I0x; b, Magnification $40 x$.

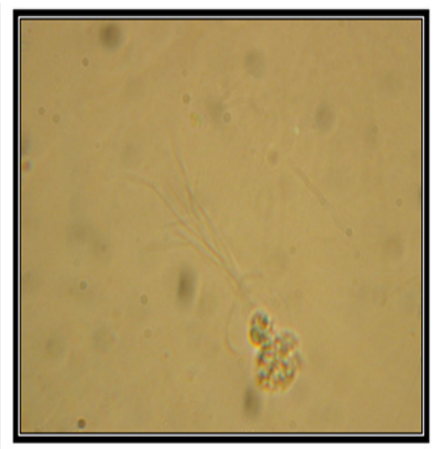

Figure 2 Polyflagellate zoospore of $\mathrm{N}$. frontalis.

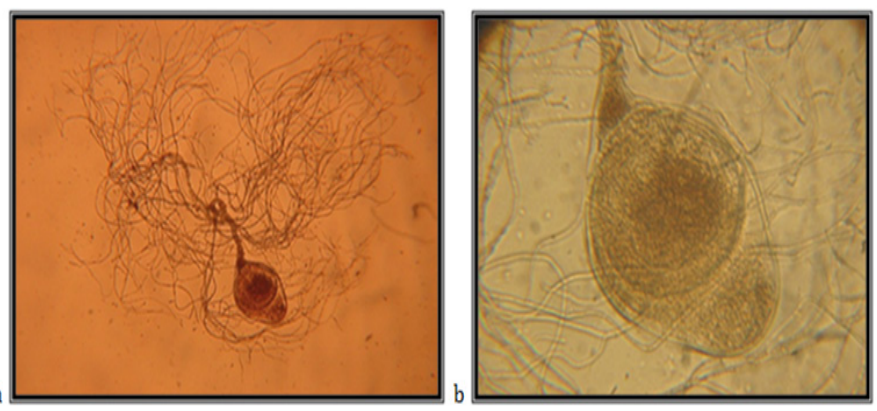

Figure 3 Strain EZ2- N. frontalis. Monocentric thallus with short egg-like sporangiophore. a. Magnification I0x; b. Magnification 40x.

\section{Isolate EZ3}

Zoosporangia, asymmetrically spheric, $161.24 \mu \mathrm{m}$ in diameter; widespread rhizoid, the neck is not narrowed or slightly narrowed, the main axis, close to the sporangium, up to $14.28 \mu \mathrm{m}$ in diameter, coiled; the main rhizoid is often coiled; rhizoid system is spread up to $600 \mu \mathrm{m}$ in diameter; zoospores are liberated through side pore, accompanied by fast decomposition and cracking of the sporangium wall; zoospores are variable in length and shape; spheric zoospores, polyflagellates.

The isolate is taken from feces of a fallow deer (Cervus dama), kept in the ZOO, Skopje. Accordingly the key to determine the anaerobic fungi of ${ }^{13}$ the description of the isolate corresponds completely to the description of Neocallimastix spp (Figure 4) (Figure 5).
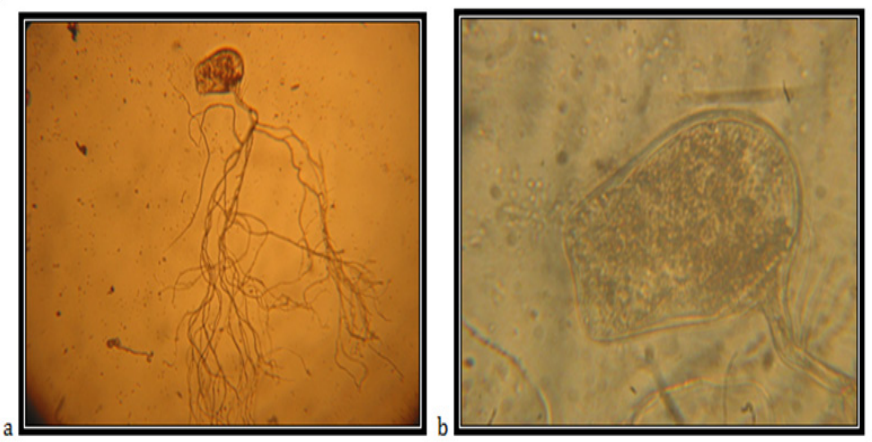

Figure 4 Strain EZ3- Monocentric thallus with zoosporangium, in the moment of liberation of zoospores. a. Magnification I0x; b. Magnification 40x.

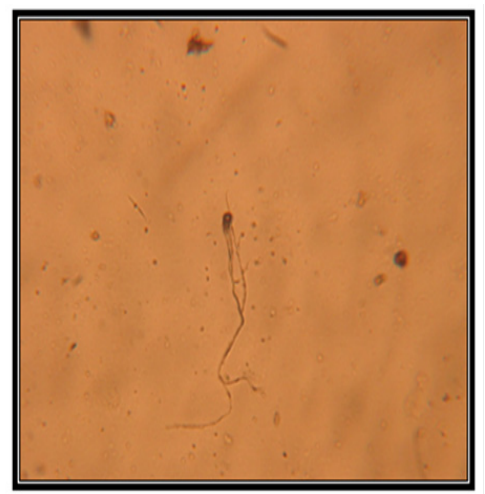

Figure 5 Neocallimastix spp- polyflagellate zoospore.

\section{Isolate EJ I}

Zoosporangia, symmetrically spheric, $119.99 \mu \mathrm{m}$ in diameter; widespread rhizoid, the neck is slightly narrowed, the main axis, close to the sporangium, up to $25.71 \mu \mathrm{m}$ in diameter, coiled; the main rhizoid is often coiled; rhizoid system is spread up to $800 \mu \mathrm{m}$ in diameter; zoospores are liberated through side pore, accompanied by fast decomposition and cracking of the sporangium wall, which is clearly double-layered; zoospores are variable in length and shape; spheric zoospores, polyflagellates.

The isolate is taken from feces of a fallow deer (Cervus dama), kept in the Protected Nature Reserve Jasen, Skopje. Accordingly the key to determine the anaerobic fungi of ${ }^{13}$ the description of the isolate corresponds completely to the description of Neocallimastix spp (Figure 6).
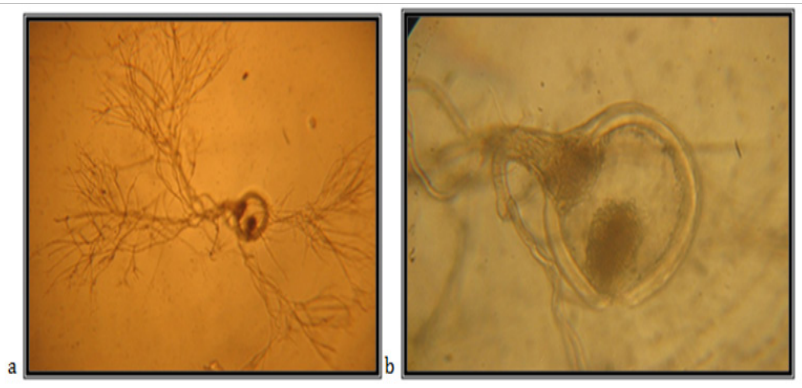

Figure 6 Strain EJI- Monocentric thallus with zoosporangium in the moment of liberation of zoospores. a. Magnification 10x; b. Mgnification 40x. 


\section{Isolate SZ I}

Monocentric sporangia, double pear-like $31 * 115 \mu \mathrm{m}$; with several papillae; the main rhizoid is filamentously spread, it elongates up to $180 \mu \mathrm{m}$, discharge follows after the decomposition of the papillae; zoospores are ovoid, 3.1-8.0 $\mu \mathrm{m}$, uniflagellate. The isolate is taken from feces of a roe deer (Capreolus capreolus), kept in the ZOO, Skopje. Accordingly the key to determine the anaerobic fungi of ${ }^{13}$ the description of the isolate corresponds completely to the description of Piromyces mae.

In Malaysia, $P$. mae has been isolated from the rumen and feces of oxen, buffalos, sheep and goats, as well as from the duodenum of the sheep. Also, this type has been isolated from the rumen of Elk in Canada $^{16}$ and in the rumen of sheep in France ${ }^{21}$ (Figure 7) (Figure 8).
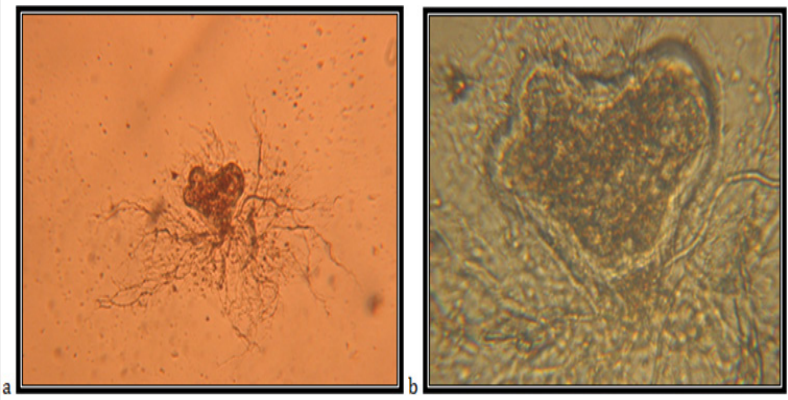

Figure 7 Strain SZI- Piromyces mae, endogenous sporangium with two papillae. a. Magnification I0x; b. Magnification 40x.

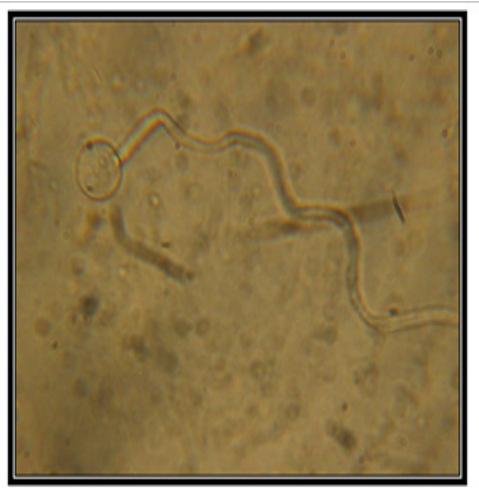

Figure 8 Uniflagellate zoospores- P. mae.

\section{Isolate SJ |}

Monocentric sporangia, heart-like, $48 * 89 \mu \mathrm{m}$; with several papillae; the main rhizoid is filamentously branched, it elongates up to $330 \mu \mathrm{m}$, discharge follows after the decomposition of one or two papillae; zoospores are spheric to ovoid, uniflagellate.The isolate is taken from feces of a roe deer (Capreolus capreolus), kept in the Protected Nature Reserve Jasen, Skopje. Accordingly the key to determine the anaerobic fungi of ${ }^{13}$ the description of the isolate corresponds completely to the description of Piromyces mae (Figure 9).

\section{Isolate EJ2}

Monocentric sporangia, endogenous, with diameter of $97 \mu \mathrm{m}$; the main rhizoid is large, $583.13 \mu \mathrm{m}$ in diameter, without constrictions or slightly constricted in the neck area, branched with constrictions on the rhizoid; zoospore examination is with decomposition of a wide apical part of the wall; zoospores are quite variable in the shape, uniflagellate. The isolate is taken from feces of a fallow deer (Cervus dama), kept in the Protected Nature Reserve Jasen, Skopje. Accordingly the key to determine the anaerobic fungi of ${ }^{13}$ the description of the isolate corresponds completely to the description of Piromyces communis.

In Malaysia, $P$. communis has been isolated from the rumen of sheep, goat, ox, water buffalo and deer, and from the duodenum of the sheep. ${ }^{22}$ The coil of the main rhizoid is often found in the endogeneous forms. Piromyces communis is, also isolated from the rumen of sheep in Great Britain, ${ }^{23}$ and France, ${ }^{24}$ as well as from the rumen of oxen in Canada $^{16}$ (Figure 10).
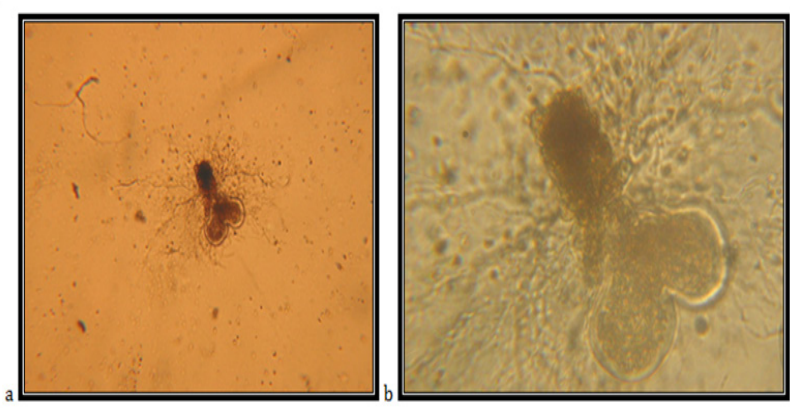

Figure 9 Strain SJI- Piromyces mae, endogenous sporangium with two papillae. a. Magnification I0x; b. Magnification 40x.

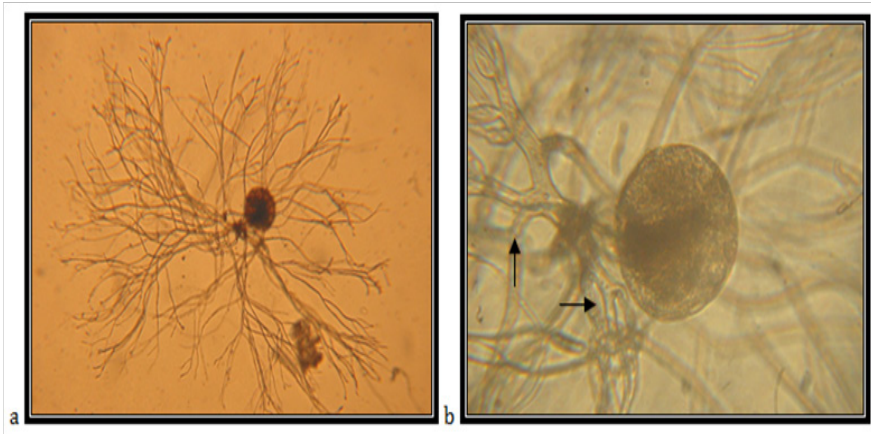

Figure 10 Strain EJ2- Piromyces communis, endogenous sporangium with coiled main rhizoid; some rhizoids are constricted (arrows). a. Magnification I0x; b. Magnification 40x.

\section{Isolate EJ3}

Monocentric sporangia, endogeneous, ellipsoid with diameter of $31.42 \mu \mathrm{m}$; rhizoids are sometimes with constrictions; the main rhizoid is usually not branched, ending in a poorly branched system; zoospores are uniflagellates. In cultures, this type is easy to differentiate from other Piromyces spp. because of how small the sporangium is. It has been found only in Malaysia, in the rumen of Javan rusa, ${ }^{25}$ goat, sheep and in the duodenum of sheep. ${ }^{22}$

The isolate is taken from feces of a fallow deer (Cervus dama), kept in the Protected Nature Reserve Jasen, Skopje. Accordingly the key to determine the anaerobic fungi of ${ }^{13}$ the description of the isolate corresponds completely to the description of Piromyces minutus (Figure 11).

\section{Isolate EJ4}

Monocenttric; sporangia are elongated and ovale, $74.28 * 51.42 \mu \mathrm{m}$; main rhizoid is filamentously branched, it elongates up to $800 \mu \mathrm{m}$; sporangium might lay on both shorter and longer sporangiophore 
without constrictions; discharge of zoospore follows after the decomposition of the sporangium wall; zoospores are spheric to ovale, 2.0-11.0 $\mu \mathrm{m}$.

The isolate is taken from feces of a fallow deer (Cervus dama), kept in the Protected Nature Reserve Jasen, Skopje. Accordingly the key to determine the anaerobic fungi of ${ }^{13}$ the description of the isolate corresponds completely to the description of Piromyces mae (Figure 12).
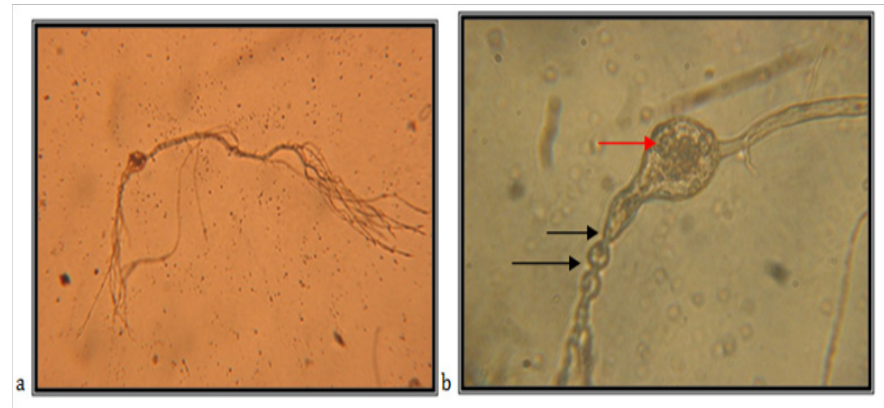

Figure I I Strain EJ3- Piromyces minutus, straight and unbranched main rhizoid terminating in sparsely-branched rhizoids. Main rhizoid with constriction (black arrows). Red arrow- zoospores. a. Magnification I0x; b. Magnification $40 x$.

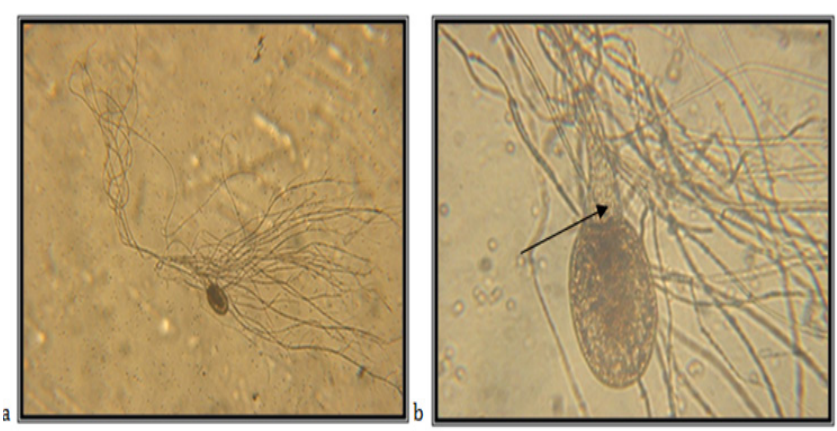

Figure I 2 Strain EJ4- Piromyces mae, sporangium with short sporangiophore (arrow). a. Magnification I0x; b. Magnification 40x.

\section{Isolate SJ2}

Monocenttric; sporangia are strictly endogeneous, ellipsoid or in a shape of pear, with diameter of $171 \mu \mathrm{m}$; main rhizoid is not branched, ending in a branched system; zoospore discharge follows after a wide apical pore, occasionally two pores of a large sporangium; zoospores are uniflagellates.

In cultures, this type is easy to differentiate from other Piromyces spp. because of how small the sporangium is. It has been found only in Malaysia, in the rumen of Javan rusa, ${ }^{25}$ goat, sheep and in the duodenum of sheep. ${ }^{22}$ The isolate is taken from feces of a fallow deer (Cervus dama), kept in the Protected Nature Reserve Jasen, Skopje. Accordingly the key to determine the anaerobic fungi of ${ }^{13}$ the description of the isolate corresponds completely to the description of Piromyces minutus (Figure 13).

\section{Isolate $\mathbf{Z} \mathbf{2}$}

Endogenously developed zoosporangia, spheric, $83.61 \mu \mathrm{m}$ in diameter; rhizoids mainly come over from one axis, occasionally two or three at the same side of the sporangium, the neck is wide; the main axis close to the sporangium, up to $32 \mu \mathrm{m}$ in diameter, coiled; main rhizoid is often coiled; rhizoid system is spread up to $1 \mathrm{~mm}$ in diameter, zoospores are liberated through apical pore, accompanied by fast decomposition and cracking of the sporangium wall; zoospores are variable in length and shape, spheric zoospores $7-22 \mu \mathrm{m}$ in diameter, with 7 to around 30 flagella.

The isolate is taken from feces of a zebu (Bos indicus), kept in the ZOO in Skopje. Accordingly the key to determine the anaerobic fungi of ${ }^{13}$ the description of the isolate corresponds completely to the description of Neocallimastix frontalis (Figure 14) (Figure 15).
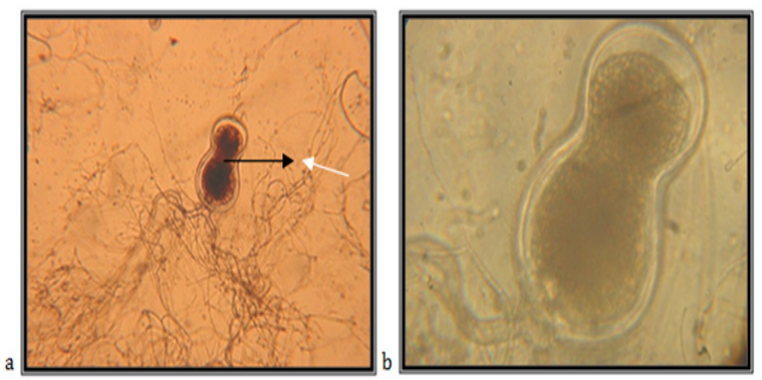

Figure 13 Strain SJ2- Piromyces minutus, rhizoid system with two main rhizoids. Arrows shows two-layer wall of sporangiophore, full of spores. a. Magnification I0x; b. Magnification 40x.

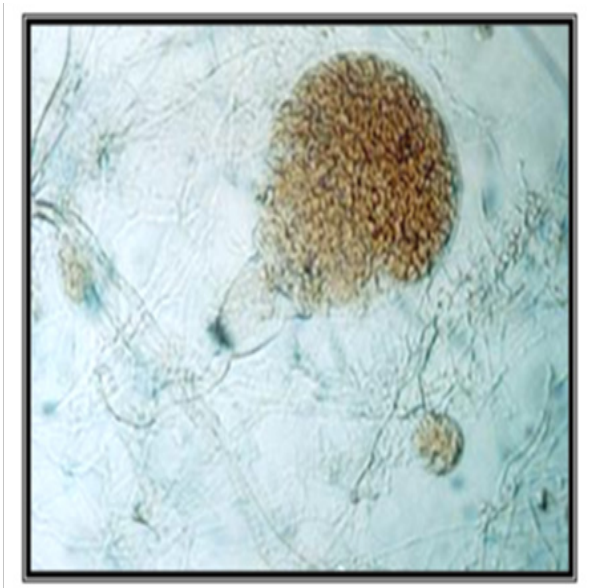

Figure I4 Strain Z2- Neocallimastix frontalis, exogenous sporangium with short, egg-like sporangiophore, full with spores. Magnification 900x.

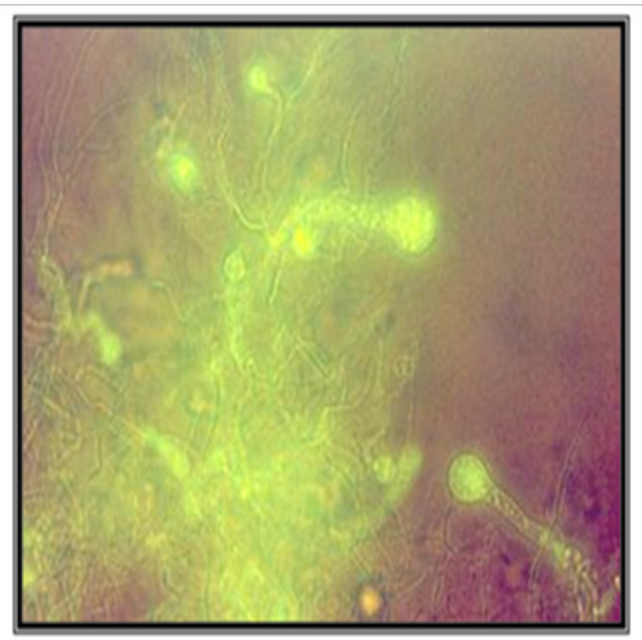

Figure I5 Strain Z2- Neocallimastix frontalis, under fluorescent microscopy. Magnification 400x. Fluorescence occur in nuclei. 


\section{Isolate L2}

Mycelium with undetermined length is raised above the zoospore cyst in germination; polycentric. Zoospores were not found. Constrictions of the hyphas are in the shape of isthmus. Only because of the absence of zoospores, were we not able to determine for sure what genus of polycentric anaerobic fungi they were; but the presence of constrictions in shape of isthmus which are correctly positioned, means that these are polycentric fungi of genus Anaeromyces. The isolate is taken from the feces of llama (Lama glama), kept in ZOO, Skopje (Figure 16) (Figure 17).

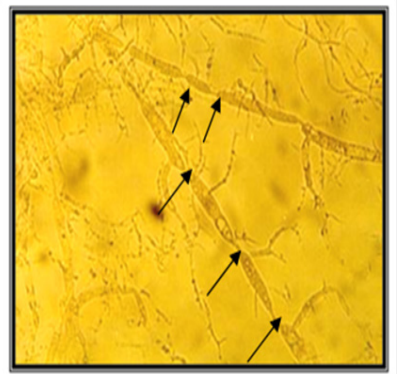

Figure I6 Strain L2-Anaeromyces spp., polycentric strain. Magnification 400x. Arrows- constricted hiphas.

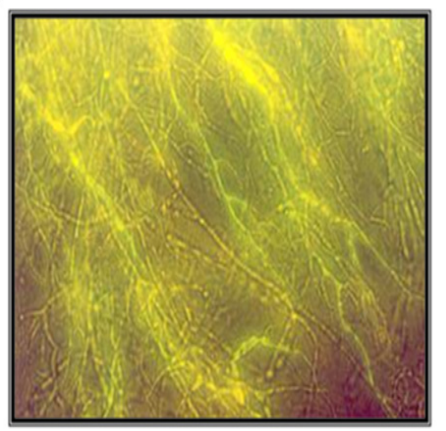

Figure 17 Strain L2- Anaeromyces spp., polycentric strain under fluorescent microscopy. Magnification 400x. Fluorescence occur in nuclei.

\section{Isolate J2}

Single longitudinal sporangia, $28 * 106 \mu \mathrm{m}$, in the shape of bobbin (with apical bud), formed on sporangiophores, uniflagellates zoospores, and hyphas-constricted. The isolate is taken from feces of a domestic yak (Bos gruniens), kept in the ZOO in Skopje. Accordingly the key to determine the anaerobic fungi of ${ }^{13}$ the description of the isolate corresponds completely to the description of Anaeromyces elegans. This type can be often found in the rumen of oxen and buffalos in Malaysia (Figure 18) (Figure 19).

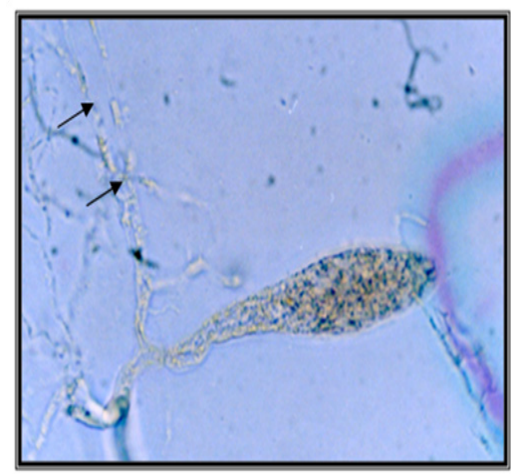

Figure I 8 Strain J2- Anaeromyces elegans, polycentric strain. Magnification 450x. Arrows- constricted hiphas.

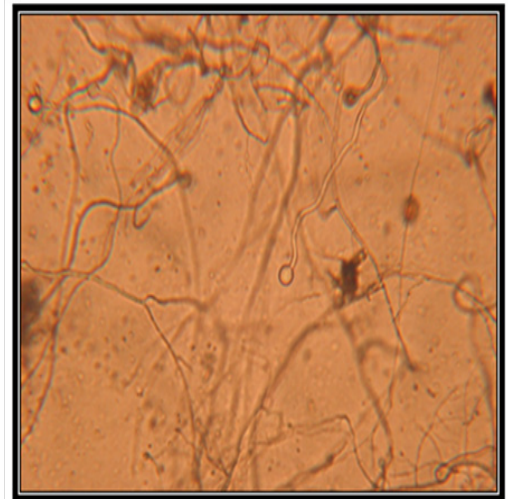

Figure 19 Uniflagellate zoospores- strain J2. Magnification 40x

\section{Isolate V4}

Mycelium with undetermined length is raised above the zoospore cyst in germination; polycentric. Zoospores were not found. Constrictions of the hyphas. Only because of the absence of zoospores, were we not able to determine for sure what genus of polycentric anaerobic fungi they were.

The isolate is taken from the feces of watusi (Bos vatusi), kept in the ZOO in Skopje. Accordingly the key to determine the anaerobic fungi of ${ }^{13}$ the description of the isolate corresponds completely to the description of polycentric genus of anaerobic fungi Orpinomyces spp. or Anaeromyces spp (Figure 20).

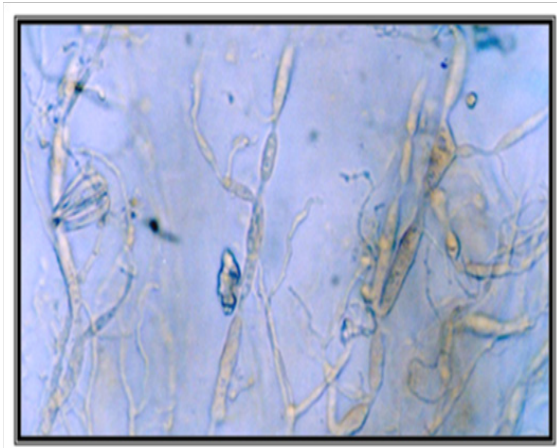

Figure 20 Strain V4- polycentric strain. Magnification 450x.

\section{Isolate BO3}

Monocentric; sporangia are double pear-like (heart-like), 39$61 * 89-128 \mu \mathrm{m}$, with several papillae; main rhizoid is filamentously branched, elongated to $450 \mu \mathrm{m}$; discharge follows after one or two papillae; spheric zoospores, $2.0-12.5 \mu \mathrm{m}$, uniflagellate, rarely two to four flagella. The isolate is taken from the feces of a barbary sheep (Ammotragus lervia), kept in the ZOO in Skopje. Accordingly the key to determine the anaerobic fungi of ${ }^{13}$ the description of the isolate corresponds completely to the description of Piromyces mae (Figure 21).

\section{Isolate ES |}

Filamentous fungus, with monocentric thallus; with double oval sporangia which are kept on one sporangium with diameter of around $77 \mu \mathrm{m}$. When they are mature, the upper half of the sporangium opens and zoospores are liberated. Zoospores have a diameter of $7.3 \mu \mathrm{m}$; uniflagellate.

The isolate is taken from the feces of a red deer (Cervus elaphus), kept in the ZOO in Skopje. Accordingly the key to determine the 
anaerobic fungi of $^{13}$ the description of the isolate corresponds completely to the description of Piromyces citronii (Figure 22).

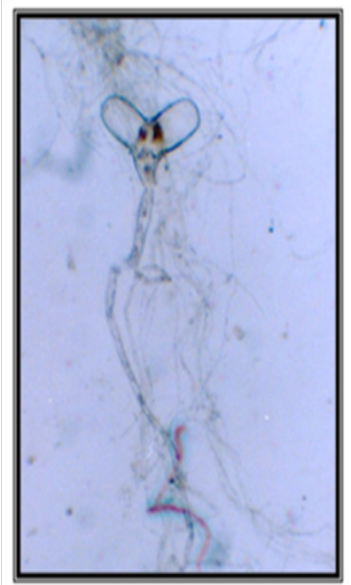

Figure 21 Strain BO3- Piromyces mae, endogenous sporangium with two papillae. Magnification 450x.

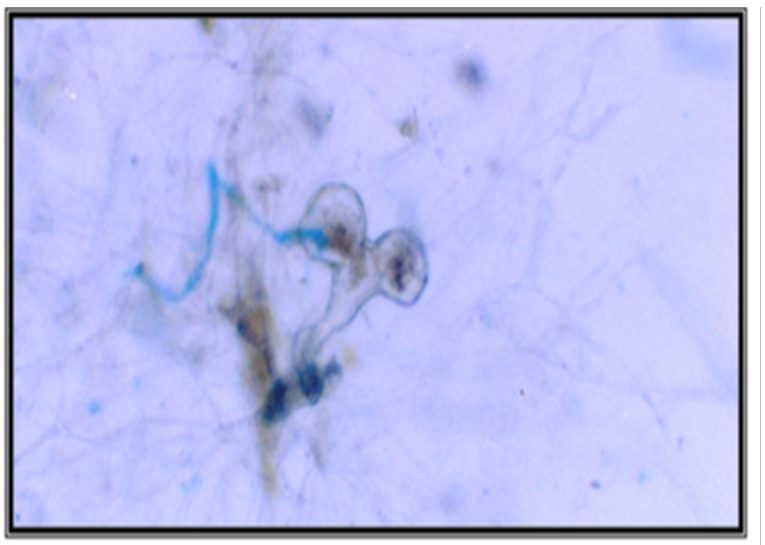

Figure 22 Strain ESI- Piromyces citronii, monocentric thallus. Magnification 450x.

\section{Isolate J I}

Monocentric; sporangia are elongated; main rhizoid is filamentously branched, elongated to $450 \mu \mathrm{m}$; spheric zoospores, $2.0-12.3 \mu \mathrm{m}$, uniflagellate, rarely two to four flagella. The isolate is taken from the feces of a yak (Bos gruniens), kept in the ZOO in Skopje. Accordingly the key to determine the anaerobic fungi of ${ }^{13}$ the description of the isolate corresponds completely to the description of Piromyces mae (Figure 23).
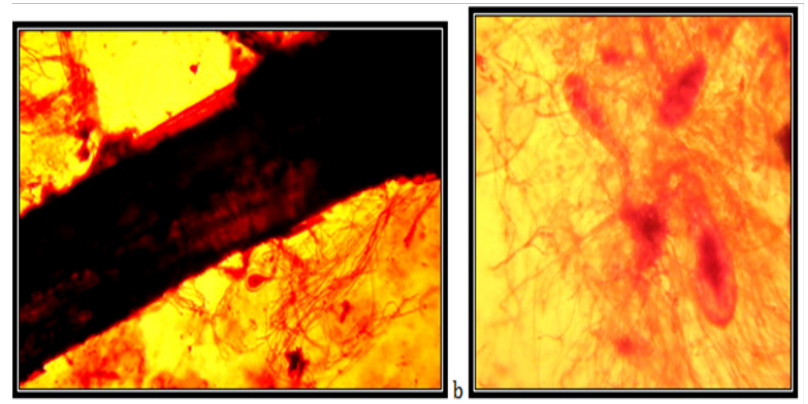

Figure 23 Strain JI- Piromyces mae, monocentric strain. a. Sporangiums on digested piece of straw; magnification I0x; b. Magnification 40x.

\section{Isolate J3}

Endogenously developed zoosporangia, ovally elongated; rhizoids mainly come over from one axis, occasionally two or three at the same side of the sporangium, the neck is wide; the main axis close to the sporangium, up to $18 \mu \mathrm{m}$ in diameter, coiled; main rhizoid is often twirld; rhizoid system is spread up to $1 \mathrm{~mm}$ in diameter, zoospores are liberated through apical pore, accompanied by fast decomposition and cracking of the sporangium wall; zoospores are variable in length and shape, $5-18 \mu \mathrm{m}$ in diameter, with 7 to around 30 flagella.

The isolate is taken from the feces of a yak (Bos gruniens), kept in the ZOO in Skopje. Accordingly the key to determine the anaerobic fungi of ${ }^{13}$ the description of the isolate corresponds completely to the description of Neocallimastix frontalis (Figure 24).
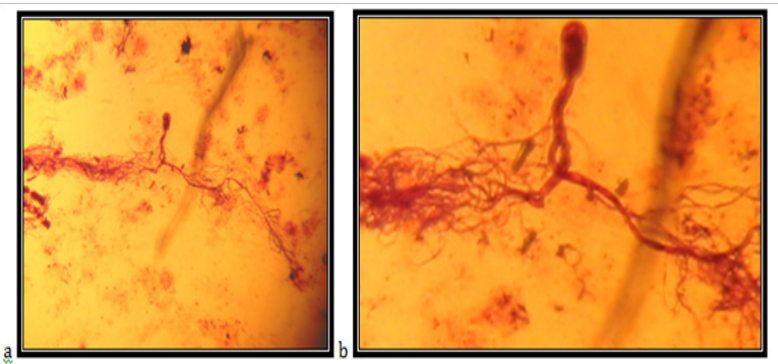

Figure 24 Strain J3- Neocallimastix frontalis, sporangium on long sporangiophore, full with spores. a. Magnification I0x; b. Magnification 40x.

\section{Isolate MR I}

Endogenously developed zoosporangia, spheric with diameter of $42 \mu \mathrm{m}$; rhizoids mainly come over from one axis, occasionally two or three at the same side of the sporangium, the neck is wide; the main axis close to the sporangium, up to $15 \mu \mathrm{m}$ in diameter, coiled; main rhizoid is often coiled; rhizoid system is spread up to $1 \mathrm{~mm}$ in diameter, zoospores are liberated through apical pore, accompanied by fast decomposition and cracking of the sporangium wall; zoospores are variable in length and shape, often spheric, with 7 to around 30 flagella.

The isolate is taken from the feces of a moufflon (Ovis musimon), kept in the Protected Nature Reserve Jasen, Skopje. Accordingly the key to determine the anaerobic fungi of ${ }^{13}$ the description of the isolate corresponds completely to the description of Neocallimastix frontalis (Figure 25).
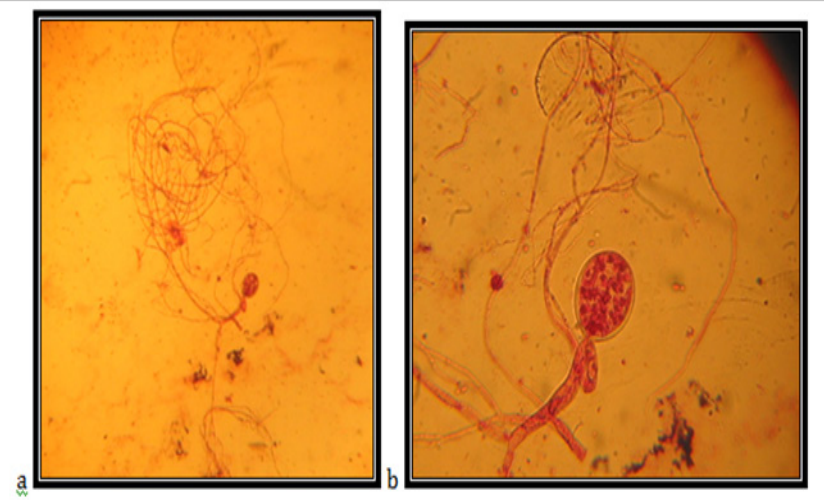

Figure 25 Strain MRI- Neocallimastix frontalis, sporangium with long sporangiophore, with spores. a. Magnification I0x; b. Magnification 40x. 


\section{Conclusion}

The study reveals that 19 isolates of obligatory anaerobic fungi, which have been isolated during the preparation of this study. The description is based completely on the thallus morphology, as seen through the light microscope, in order to enable functional identification of genera and phyla. Among these, three isolates are identified as polycentric, and 16 are identified as monocentric. The present study gives a baseline data of biodiversity of anaerobic fungi from ruminants in Republic of Macedonia.

\section{Acknowledgements}

None.

\section{Conflict of interest}

The authors declare that there is no conflict of interests to declare regarding the publication of this paper.

\section{References}

1. Kamra DN. Rumen microbial ecosystem. Current Science. 2005;89(1):124-135.

2. Munn EA. The ultrastructure of anaerobic fungi. In: Orpin CG, Mountfort DO, editors. The anaerobic fungi. Marcel Dekker, New York, USA; 1994. p. 47-105.

3. Barr DJS. Thezoosporic grouping of plant pathogens. In: Buczacki T, editor. Zoosporic plant pathogens. Academic Press, London, UK; 1983. p. 161-192.

4. Ozkose E, Thomas BJ, Davies DR, et al. Cyllamycesaberensisgen.nov. sp.nov., a new anaerobic gut fungus with branched sporangiophores isolated from cattle. Can J Bot. 2001;79(6):666-673.

5. Hungate RE. The Rumen and its Microbes. Academic Press, London, UK; 1966. p. 544

6. Hungate RE. A roll-tube method for the cultivation of stict anaerobes. Methods Microbiol. 1969;3B:117-132.

7. Bryant MP. Commentary on the hungate technique for culture of anaerobic bacteria. Am J Clin Nutr. 1972;25(12):1324-1328.

8. Leedle JAZ, Hespell RB. Differential carbohydrate media and anaerobic replica plating techniques in delineating carbohydrate utilizing subgroups in rumen bacterial populations. Appl Environ Microbiol. 1980;39(4):709-719.

9. Lowe SE, Theodorou MK, Trinci APJ, et al. Growth of anaerobic rumen fungi on defined and semi-defined media lacking rumen fluid. $J$ Gen Microbiol. 1985;131:2225-2229.

10. Caldwell DR, Bryant MP. Medium without rumen fluid for nonselective enumeration and isolation of rumen bacteria. Appl Microbiol. 1966;14(5):794-801.
11. Theodorou MK, Trinci APJ. Procedures for the isolation and culture of anaerobic fungi. In: Nolan JV, Leng RA, editors. The roles of protozoa and fungi in ruminant digestion. Armidale, New South Wales, AUS; 1989. p. $145-152$.

12. Theodorou MK, Gill M, King-Spooner C, et al. Enumeration of anaerobic chytridiomycetes as thallus forming units: a novel method for the quantification of fibrolytic fungal populations from the digestive tract ecosystem. Applied and Environmental Microbiology. 1990;56(4):1073-1078.

13. Ho WY, Barr DJS. Classification of anaerobic gut fungi from herbivores with emphasis on rumen fungi from Malaysia. Mycologia. 1995;87(5):655-677.

14. Ho YW, Barr DJS, Abdullah N, et al. A new species of Piromyces from the rumen of deer in Malaysia. Mycotaxon. 1993;47:285-293.

15. Bauchop T. Rumen anaerobic fungi of cattle and sheep. Appl Environ Microbiol. 1979;38(1):148-158.

16. Barr DJS, Kudo H, Jakober KD, et al. Morphology and development of rumen fungi: Neocallimastix sp., Piromyces communis and Orpinomyces bovis gen. nov., sp. nov. Can J Bot. 1989;67(9):2815-2824.

17. Phillips MW. Unusual rumen fungi isolated from northern Australian cattle and water buffalo. In: Nolan JV, Leng $R A$, editors. The roles of protozoa and fungi in ruminant digestion. Armidale, New South Wales, AUS; 1989. p. 247-250.

18. Barichievich EM, Calza RE. Media carbon induction of extracellular cellulase activities in Neocallimastix frontalis EB188. Curr Microbiol. 1990;20(4):265-271.

19. Orpin CG. Studies on the rumen flagellate Neocallimastix frontalis. $J$ Gen Microbiol. 1975;91(2):249-262.

20. Lowe SE, Griffith GW, Milne A, et al. The life cycle and growth kinetics of an anaerobic rumen fungus. J Gen Microbiol. 1987;133:1815-1827.

21. Gaillard-Martinie B, Breton A, Dusser M, et al. Contribution to the morphological, cytological, and ultrastructural characterization of Piromyces mae, a strictly anaerobic rumen fungus. Curr Microbiol. 1992;24(3):159-164.

22. Ho YW, Khoo IYS, Tan SG, et al. Izozyme analysis of anaerobic rumen fungi and their relationship to aerobic chytrids. Microbiology. 1994;140(6):1495-1504.

23. Orpin CG. Invasion of plant tissue in the rumen by the flagellate $\mathrm{NeO}$ callimastix frontalis. J Gen Microbiol. 1977;98(2):423-430.

24. Gaillard B, Citron A. Ultrastructural study of two rumen fungi: $P i$ romonas communis and Sphaeromonas communis. Curr Microbiol. 1989;18(2):83-86.

25. Ho YW, Barr DJS, Abdullah N, et al. Neocallimastix variabilis, a new species of anaerobic fungus from the rumen of cattle. Mycotaxon. $1993 ; 46: 241-258$. 